\title{
Clipless Laparoscopic Cholecystectomy: Ultrasonic Dissection vs Conventional Method
}

\author{
Laligen Awale ${ }^{1}$, Narendra Pandit ${ }^{2}$, Shailesh Adhikary ${ }^{3}$
}

\begin{abstract}
Introduction: Laparoscopic cholecystectomy (LC) is now the gold standard treatment of gallstone disease, but with advancement in technology, there is always a scope for improvement. Ultrasonic shears has been shown to seal the duct and small-size vessel adequately but the fear of complication and sleepless nights has always hindered its use as the sole instrument for LC. Proper use of ultrasonic shears can provide improvement or refinement in LC.

Materials and methods: It is a randomized controlled trial conducted at BP Koirala Institute of Health Sciences, Dharan, Nepal, from 2015 to 2016 (1 year). All the patients with symptomatic gallstone disease were assessed thoroughly and randomized into the harmonic scalpel [clipless laparoscopic cholecystectomy (CLC)] or conventional laparoscopic group (CL).

Results: Over a period of 1 year, 112 patients were enrolled into CLC (53) and CL (59) groups. The demography of the patients in both the groups including age, sex, history of previous surgery, comorbid conditions, and history of acute cholecystitis was comparable. The mean operative time in our study was $38.65 \pm 13.28$ minutes. The operative time in the CLC group (35.91 \pm 11.66 minutes vs $41.12 \pm 14.23$ minutes) was less though it was not statistically significant ( $p$ 0.054). However, when the "gallbladder (GB) was not perforated," the operative time was significantly less in the CLC group ( $34.30 \pm 9.30$ minutes vs $38.70 \pm 10.76$ minutes, $p 0.03)$. In our study, three ( $2.6 \%)$ patients required conversion to open cholecystectomy. One (1.85\%) in CLC and $2(3.2 \%)$ in the CL group ( $p$ 0.63). The visual analog score (VAS) for pain in the first 12 hours and median fall in hemoglobin was significantly less in the CLC group. In our study group, a total of seven (6.25\%) patients had morbidity and there was no mortality.
\end{abstract}

Conclusion: With the development of ultrasonic energy source and its ability to seal the vessel and cystic duct safely, it can be utilized during LC without the need of clips.

Keywords: Harmonic scapel, Laparoscopic cholecystectomy, Symptomatic cholelithiasis.

World Journal of Laparoscopic Surgery (2020): 10.5005/jp-journals-10033-1384

\section{INTRODUCTION}

Laparoscopic cholecystectomy (LC) is now the gold standard treatment of gallstone disease; ${ }^{1}$ and no doubt, presently it is one of the most commonly performed laparoscopic procedures worldwide. The advantages of this minimal invasive approach have been widely reported, showing the positive impact on the short- and long-term outcomes. With the rapid advancement in the technology, there is always new scope for improvement in the procedure.

Laparoscopic cholecystectomy is an arguably safe procedure, but there are few issues with the current technology and technique, which have been seen to increase the risk of injuries and postoperative complications. ${ }^{2}$ Standard LC is usually performed by instruments such as Maryland dissector, scissors, hook, and/ or spatula. Cystic artery and duct is most frequently occluded by simple metallic clips. Common problems include common bile duct (CBD) stone formation due to the migration of suture materials, ${ }^{3}$ bile leak due to the inappropriate clip placement or slippage of clips, ${ }^{4,5}$ lateral injury to bile duct and/or vessels from heat of monopolar cautery, ${ }^{6}$ and possibility of visceral organ injury due to the need for frequent instrumental exchange. ${ }^{6-8}$

Ultrasound shear is the vessel and duct sealing device which tackles the issue related to clips, suture, and lateral thermal injury. ${ }^{6,9}$ It can also be used as dissector, hence decreases not only the frequency of instrumental exchange and associated possibility of visceral injury but also the operative time loss during the process. It provides the surgeon with newer armamentarium in LC.
${ }^{1-3}$ Department of Surgery, Division of Gastrointestinal Surgery, BP Koirala Institute of Health Sciences, Sunsari, Nepal

Corresponding Author: Laligen Awale, Department of Surgery, Division of Gastrointestinal Surgery, BP Koirala Institute of Health Sciences, Sunsari, Nepal, Phone: +977 9841227258, e-mail: Ialijan@ hotmail.com

How to cite this article: Awale L, Pandit N, Adhikary S. Clipless Laparoscopic Cholecystectomy: Ultrasonic Dissection vs Conventional Method. World J Lap Surg 2019;12(3):120-125.

Source of support: Nil

Conflict of interest: None

Ultrasonic shears adequately seal the vessel and duct, so avoid the need of metallic clips. Minimum bleeding while dissection with this technique keeps the surgical field clear, avoiding misidentification of the structures. Substantial number of studies reports the positive or favorable outcome in closure of cystic artery and duct using the ultrasonically activated shears, ${ }^{2,9-12}$ with acceptable rate of complications. In these studies, cases of bile leak associated with this technique were reported but comparable (2-4\%) to the standard technique.

Ultrasound shear has been shown to have added benefit over the conventional technique but the fear and hesitancy still exist regarding its widespread acceptance as a sole instrument for LC. Hesitancy and fear of using it as a sole instrument for "cystic duct closure" seem to be the core issue, in spite of the adequate evidence to suggest its effective closure. In our institute, approximately 500 
patients are operated annually by the conventional laparoscopic (CL) method. Through this study, we wanted to see how effective and safe harmonic shear is in dividing the cystic duct in LC, to move forward with time, and to find if it actually confers benefit in relation to operative time, bleeding, reduced postoperative morbidity; and we also planned to embrace a new technology for the better outcome and patient's satisfaction.

\section{Materials and Methods}

It was a single institutional randomized controlled trial done at BP Koirala Institute of Health Sciences, Dharan, Nepal, for a period of 1 year (2015-2016). All the patients with symptomatic gallstone disease and between 18 years and 70 years of age were included in the study. Those patients with cholangitis, wide cystic duct $>5$ $\mathrm{mm}, \mathrm{CBD}$ stones or dilated CBD, history of jaundice, impaired liver function test, pregnant patients, and suspicion of GB malignancy were excluded from the study. Ethical clearance was taken from the Institutional Review Committee before starting the study.

All the patients presenting to the surgical outpatient department with symptomatic gallstone disease were assessed thoroughly by clinical examination and investigations. History was taken about the duration of the pain and the last episode of pain. Physical examination was done and all patients underwent transabdominal ultrasonography and the details were noted. Liver function test and hemoglobin level were done in all the patients. Other investigations including computed tomography of the abdomen and endoscopic retrograde cholangiopancreatography were done if required.

The procedure was explained in the native language to the patients and informed written consent was obtained in all cases for randomization to clipless laparoscopic cholecystectomy (CLC) or CL. Randomization was done by the person not otherwise involved in the clinical setting. Randomization was undertaken by consecutively numbered opaque sealed envelopes containing the treatment options, which were assigned with computer-generated random numbers.

Each surgeon who was participating in the study had an experience of performing at least 100 successful laparoscopic cholecystectomies. General anesthesia was administered during the procedure. The standard supine position was used for all patient, i.e., reverse Trendelenburg position with right up. Laparoscopic cholecystectomy was performed with uniform technique, including the standard four-trocar ports, a pneumoperitoneum by open method with a maximum pressure of $15 \mathrm{~mm} \mathrm{Hg}$, and a $30^{\circ}$ optic scope. Dissection of the GB was initiated at the posterior peritoneal fold and the dissection proceeded forward anteriorly to skeletonize the cystic artery and duct in the Calot's triangle.

In the CLC group, the ultracision harmonic scalpel, Ethicon Endo-Surgery, was used for dissecting the triangle of Calot (power level set at 5). For the closure and division of both the cystic duct and artery, the instrument was set at power level 2. Before ligation of cystic duct with ultrasonic shears, the size of the cystic duct and CBD were noted with the help of the jaws of the harmonic shears. After confirming the appropriate size of the cystic duct and artery, they were subsequently closed using the instrument. While closing the duct, it was made sure that the cystic duct was free of calculi by moving the jaws of harmonic scalpel proximally and distally with an intent to swipe any possible stone in cystic duct toward the GB. Then the cystic duct was placed between the jaws of the harmonic scalpel with the care to avoid injury to the CBD. The jaw was then closed till the click sound was heard. The instrument was then activated with the minimum power set at 2 , with care not to stretch or rotate the cystic duct, and it was kept activated till the GB was detached from the cystic duct. And finally the cut end of the cystic duct was checked for any possible bile leak. In the CL group, dissection of the Calot's triangle was performed with Maryland's dissector. Closure of the cystic duct and artery was achieved by applying titanium clips and dividing in-between with scissor. Mobilization of the GB from the liver bed was started posteriorly at the Calot's triangle with anterolateral traction and was preceded anteriorly. In the CLC group, dissection of the GB from the liver bed was performed by using the harmonic scalpel. In the $C L$ group, the dissection of the GB from the liver bed was performed by using the monopolar cautery (hook or spatula). Finally, the GB was removed through the subxiphoid port, and a subhepatic tube drain was inserted through the most lateral port whenever indicated (bleed/ ooze and/or bile spillage).

The operative time, intraoperative difficulties, postoperative pain scores using the VAS, and analgesic requirement at 6 hours and days 1 and 2 were all noted by an observer who was unaware of the procedure being performed. Postoperative hematocrit and hemoglobin level (postoperative day 1), duration of placement of drain (days), and postoperative complications, if any, were recorded. Gallbladder perforation and the need for placement of drain and its removal were noted. Once discharged, patients were reviewed at the end of the first postoperative week for any evidence of biliary leak (clinical examination and abdominal ultrasound when indicated). Patients were asked to follow-up with histopathological examination report at the end of first month. At the end of the first and sixth postoperative months, the clinical examination was done and abdominal ultrasonography when indicated. In addition, blood was sampled for bilirubin, amino alanine transferase, alkaline phosphatase, and gamma-glutamic transferase levels accordingly.

All the data were entered in computer and descriptive analysis was done manually, using SPSS software. For descriptive statistic percentage, mean, standard deviation, median, and interquartile range (IQR) were calculated along with graphical and tabular presentation. Inference statistics, Chi-square and independent $t$ test, was applied to find the significant difference between the groups at $95 \%$ confidential index, where $p=0.05$. For multivariate analysis $p$ valued $<0.20$, and in bivariate analysis those variables were considered for multivariate logistic regressions to find the combined risk factor for the CLC group.

\section{Results}

Over the period of 1 year, a total of 215 patients underwent LC. Forty-nine patients denied consent for randomization and 51 patients were excluded for the following reasons: 12 patients did not meet age criteria ( 7 patients were $<18$ years and 5 patients were $>70$ years), 28 had dilated common duct/cystic duct or stones, 4 each had a recent history of jaundice and impaired liver enzymes, and 3 patients had cholangitis. A total of 115 patients met the criteria and underwent randomization into either CL group or CLC group. Three patients required conversion and were not included in the analysis. We studied a total of 112 patients: 53 in the CLC group and 59 in CL group formed the study subjects.

The mean age of the patients in our study was $45.64 \pm 14.84$ years, ranging from 20 years to 70 years with a female to male ratio of 5:1. Majority [92 (82.14\%)] of the patients had multiple GB calculi. A total of $10(8.92 \%)$ patients were operated for acute calculus 
Table 1: Demography of the patients in the clipless laparoscopic cholecystectomy and conventional laparoscopic groups

\begin{tabular}{|c|c|c|c|}
\hline Variables & $\begin{array}{l}\text { CLC group (n 53) } \\
\text { (\%) }\end{array}$ & $\begin{array}{l}\text { CL group (n 59) } \\
\text { (\%) }\end{array}$ & $p$ value \\
\hline \multicolumn{4}{|l|}{ Age (mean) } \\
\hline$<30$ & $13(24.52)$ & $13(22.03)$ & 0.54 \\
\hline $31-40$ & $10(18.86)$ & $6(10.16)$ & \\
\hline $41-50$ & $12(22.64)$ & $12(20.33)$ & \\
\hline $51-60$ & 8 (15.09) & $12(20.33)$ & \\
\hline $61-70$ & $10(18.86)$ & $16(27.11)$ & \\
\hline \multicolumn{4}{|l|}{ Sex } \\
\hline Male & $10(18.86)$ & $8(13.55)$ & 0.44 \\
\hline Female & $43(81.13)$ & $51(86.44)$ & \\
\hline Previous surgery & $6(11.32)$ & $10(16.94)$ & 0.39 \\
\hline Comorbid condition & $14(26.41)$ & $18(30.50)$ & 0.63 \\
\hline Diabetes mellitus & 7 (13.2) & $5(8.47)$ & 0.41 \\
\hline Hypertension & $5(9.43)$ & $10(16.94)$ & 0.24 \\
\hline Cirrhosis & 0 & $2(3.38)$ & 0.17 \\
\hline COPD & $2(3.77)$ & $1(1.69)$ & 0.91 \\
\hline \multicolumn{4}{|l|}{ USG findings } \\
\hline Multiple calculi & $41(77.35)$ & $51(86.44)$ & 0.21 \\
\hline Solitary stone & $12(22.64)$ & $8(13.55)$ & 0.62 \\
\hline Acute cholecystitis & $4(7.54)$ & $6(10.16)$ & \\
\hline
\end{tabular}

cholecystitis and the rest [102 (91.07\%)] were electively operated for gallstone disease. Four (7.54\%) patients in the CLC group and $6(10.16 \%)$ in the $C L$ group were operated for acute calculus cholecystitis. The demographics of the patients in both the groups were comparable (Table 1).

The mean operative time was $38.65 \pm 13.28$ minutes (range 20-85 minutes). The operative time in the CLC group (35.91 \pm 11.66 minutes) was less when compared to the $\mathrm{CL}$ group (41.12 \pm 14.23 minutes), though it was not statistically significant ( $p 0.054)$. A total of 19 (17\%) patients had perforation of GB intraoperatively. The operative time was significantly less in those without $G B$ perforation ( $n 93$, mean $36.52 \pm 13.28$ minutes) than in those with GB perforation ( $n 19$, mean $49.05 \pm 13.51$ minutes) $(p<0.001)$. Seven (13.2\%) patients in the CLC group and 12 (20.33\%) in the CL group had intraoperative GB perforation ( $p 0.31$ ). The median time taken to remove the GB from its fossa in the CLC group was 6 minutes (IQR of 5-8 minutes), ranging from 3 minutes to 30 minutes; and in the $C L$ group, it was 6 minutes (IQR of 5-10 minutes), ranging from 3 minutes to 26 minutes (Table 2). The time taken to remove GB from the fossa was not statistically significant between the two groups ( $p$ 0.23).

The operative time when compared between patients "who had GB perforation" in the two groups, the CL group took more time but was not statistically significant $(50.58 \pm 14.44$ minutes vs $46.42 \pm 12.85$ minutes in CLC group; $p$ 0.34). However, when the "GB was not perforated," the operative time was $34.30 \pm 9.30$ minutes (range 25-80 minutes) in the CLC group and $38.70 \pm 10.76$ minutes (range 20-65 minutes) in the CL group. The operative time was statistically significantly less in the CLC group ( $p 0.03$ ) when the GB was not perforated (Table 3).

In all 19 (17\%) patients required placement of the drain, 6 (11.32\%) in the CLC group and 13 (22.03\%) patients in the CL group ( $p$ 0.13). It was kept mainly after difficult dissection which had
Table 2: Intraoperative findings

\begin{tabular}{|c|c|c|c|}
\hline Variables & CLC group (n 53) & $C L$ group (n 59) & $p$ value \\
\hline Operative time (mean) & $35.91 \pm 11.66$ & $41.12 \pm 14.23$ & 0.054 \\
\hline $\begin{array}{l}\text { Gallbladder } \\
\text { perforation (mean) }\end{array}$ & $7(13.20 \%)$ & $12(20.33 \%)$ & 0.31 \\
\hline $\begin{array}{l}\text { GB removal time } \\
\text { (median) }\end{array}$ & $6(5-8)$ & $6(5-10)$ & 0.23 \\
\hline Drain placement & $6(11.32 \%)$ & $13(22.03 \%)$ & 0.13 \\
\hline Conversion & $1(1.85 \%)$ & $2(3.2 \%)$ & 0.63 \\
\hline
\end{tabular}

Table 3: Operative time in clipless laparoscopic cholecystectomy and conventional laparoscopic groups with and without gallbladder perforation

\begin{tabular}{llll}
\hline Operative time & CLC group & CL group & p value \\
\hline $\begin{array}{l}\text { With GB perforation } \\
\text { (mean) }\end{array}$ & $46.42 \pm 12.85$ & $50.58 \pm 14.44$ & 0.34 \\
$\begin{array}{l}\text { Without GB perforation } \\
\text { (mean) }\end{array}$ & $34.30 \pm 9.30$ & $38.70 \pm 10.76$ & 0.03 \\
\hline
\end{tabular}

oozing or bile stain and when some collection was anticipated in the postoperative period. The drains were usually removed on second postoperative day (range 1-14 days) and the total days required to remove the drain was not significant $(p 0.65)$ between the groups (Table 2). Three (2.6\%) patients required conversion to open cholecystectomy in our study, i.e., One $(1.85 \%)$ in the $\mathrm{CLC}$ group and two (3.2\%) in the $\mathrm{CL}$ group. The one in the CLC group had obscured anatomy with frozen Calot's triangle and an enlarged cystic node. The reason for conversion in the $\mathrm{CL}$ group was intraoperative bleeding not controllable laparoscopically and the other one had a dilated CBD with multiple calculi requiring a choledochoduodenostomy.

All the patients (100\%) in the study group required an analgesic in the first 12 hours and majority 109 (97.32\%) asked for analgesia in the first 24 hours. Fifty-one (96.22\%) patients in CLC and 58 (98.3\%) in CL group asked for analgesia in the first 24 hours (0.49). The VAS for pain in the first 12 hours postoperatively was significantly ( $p<$ 0.05 ) less statistically in the CLC group (Table 4). The VAS for pain at 24 hours postoperatively was also less in the CLC group $(2.5 \pm$ 0.8 vs $2.97 \pm 0.87$ ) though it was not statistically significant $(p 0.50)$ and after the first week, it was comparable in both the groups (CLC $1.16 \pm 0.47$ vs $1.10 \pm 0.30 ; p 0.55)$.

The amount of blood loss as demonstrated by the median fall in hemoglobin level was significantly $(p 0.001)$ less in the CLC group (Table 4). Majority of the cases [88 (78.57\%)] were discharged on the first postoperative day following surgery and in both the groups, patients were discharged on the same postoperative days ( $p$ 0.23). In our study group, a total of seven (6.25\%) patients had morbidity following surgery: two (3.77\%) in the CLC group and five $(8.47 \%$ ) in the CL group ( $p 0.44)$. In the CLC group, we had one case $(1.88 \%)$ each with port site infection and bilious drainage. In the $C L$ group, two cases (3.38\%) each with port site infections and bilious drainage followed by one (1.69\%) with chest infection. There were three $(2.67 \%)$ cases of port site infection. All of them required removal of suture and were managed with daily dressings. One in the $C L$ group had deep surgical site infection in the epigastric port, which was managed with wound trimming and irrigation under local anesthesia, allowed to heal by secondary intention, and discharged on the fourth postoperative day. All the patients were without any adverse consequences in the follow-up and the 
Table 4: Postoperative parameters in the clipless laparoscopic cholecystectomy and conventional laparoscopic groups

\begin{tabular}{lllc}
\hline Variables & CLC group (53) & CL group (59) & p value \\
\hline Analgesic requirement & & & \\
$\quad 12$ hours & $53(100 \%)$ & $59(100 \%)$ & - \\
$\quad 24$ hours & $51(96.22 \%)$ & $58(98.3 \%)$ & 0.49 \\
VAS (mean) & & & \\
$\quad 12$ hours & $3.91 \pm 0.94$ & $5.31 \pm 1.65$ & $<0.001$ \\
$\quad 24$ hours & $2.5 \pm 0.80$ & $2.97 \pm 0.87$ & 0.50 \\
$\quad 1$ week & $1.17 \pm 0.47$ & $1.10 \pm 0.30$ & 0.055 \\
Hemoglobin (g/dL) & & & \\
$\quad \begin{array}{l}\text { Preoperative (mean) } \\
\quad 12.50 \pm 1.44\end{array}$ & $12.02 \pm 1.42$ & 0.85 \\
$\quad \begin{array}{l}\text { Postoperative (mean) } \\
\text { Fall in Hb (median) }\end{array}$ & $12.12 \pm 1.44$ & $11.23 \pm 1.34$ & 0.60 \\
$\begin{array}{l}\text { Drain removal (median) } \\
\text { days }\end{array}$ & $2(2-3.75)$ & $2(2-4.5)$ & 0.52 \\
$\begin{array}{l}\text { Hospital stay (median) } \\
\text { days }\end{array}$ & $1(1-1)$ & $1(1-2)$ & 0.23 \\
$\begin{array}{l}\text { Morbidity } \\
\text { Bilious drain }\end{array}$ & $2(3.77 \%)$ & $5(8.47 \%)$ & 0.44 \\
$\begin{array}{l}\text { Port-site infection } \\
\text { Chest infection }\end{array}$ & $1(1.88 \%)$ & $2(3.38 \%)$ & 0.62 \\
\hline
\end{tabular}

wound gap was closed subsequently in the presence of healthy granulation tissues.

Three $(2.67 \%)$ patients in our study had bilious drainage, consisting of one in the CLC group and two in the CL group. The one in the CLC group developed abdomen pain, distension, multiple episodes of vomiting along with tachycardia on the first postoperative day. On ultrasound imaging, she had collection in the subhepatic space, and diagnostic aspiration revealed bile and was managed with pigtail catheter and drainage. Her drain was removed on the sixth day and discharged on the seventh postoperative day. The other two patients in the $\mathrm{CL}$ group were found to have bile in the drain postoperatively but were managed conservatively as the collection was localized, with no evidence of peritonitis or sepsis. In one patient, the drain output turned out to be serous on the third day and it was removed after ultrasound of no collection. Another patient was found to have bilious drain on the second postoperative day. She continued to have low output (50-70 mL/day) bilious drainage and did not have sepsis and hence discharged with drain on the eighth postoperative day. She was kept on regular follow-up. Her drain was removed on the 14th day when it was dry for 24 hours and also after ultrasound confirmation of no intra-abdominal collection. All three patients were doing well at 1 month follow-up. There was no jaundice or abdominal symptoms. The morbidity was similar in both the groups ( $p 0.44)$, without mortality in either group (Table 4).

\section{Discussion}

Laparoscopic cholecystectomy has now become the gold standard treatment for gallstone disease but is not without flaws. With the development of new vessel sealing devices, research are done continuously to minimize the shortcomings. In our study, we compared the $\mathrm{CL}$ technique with $\mathrm{CLC}$ using harmonic scalpel to seal both the cystic artery and the cystic duct.
Cholelithiasis is most reported among the middle-aged fertile female. ${ }^{2,13,14}$ According to our study, the mean age-group was 45.64 \pm 14.84 years and $83.9 \%$ was female, with a female to male ratio of 5:1. Adhesion following previous surgery is a known hurdle during LC, which not only increases the risks of injury but also prolongs operative time by additional need for dissection and bleeding, finally influencing the outcome. In our study, 16 (14.28\%) patients had a previous history of surgery, i.e., 6 (11.32\%) in CLC and 10 (16.94\%) in CL group, which was similar to the study by Jain et al. ${ }^{12}$ where harmonic scalpel to CL ratio for "history of previous surgery" was 8:9. In our study, 10 (8.92\%) patents underwent emergency surgery for acute cholecystitis, 4 (7.54\%) in the CLC group and 6 (10.16\%) in the CL group. The low incidence in our study is because we avoided early surgery, though several meta-analysis showed that early LC not only decreases the length of hospital stay but also prevents disease relapse without any increase in the complication rate. $^{13-17}$ Several retrospective series, in fact, demonstrated the advantages of the use of harmonic scalpel in acute cases, because of its ability to maintain hemostasis and effectiveness in closure of the duct. ${ }^{2,17-19}$ Few (8.92\%) of our patients underwent emergency surgery and hence were not included in the study.

The mean operative time in our study was $38.65 \pm 13.28$ minutes, ranging from 20 minutes to 85 minutes. The operative time in the CLC group ( $35.91 \pm 11.66$ minutes) was less than that in the $\mathrm{CL}$ group ( $41.12 \pm 14.23$ minutes), though it was not statistically significant ( $p$ 0.054). It was slightly longer, according to Bessa et al. $^{20}$ [Harmonic Scalpel (HS) 18-75 mean 32 vs conventional laparoscopic cholecystectomy (CC) $21-85$ mean 40 and $p<0.001$, but our time was similar to that of Kandil et al. ${ }^{21}$ (33.21 + 9.6 vs. 51.7 +13.79 , HS and CL, respectively, $p 0.001$ ). This shorter operative time in the CLC group is because of the added benefit of the harmonic ACE: (a) it is the multifunctional device (dissection and closure of artery and duct) and hence minimizes the need for instrumental exchange, thereby minimizing the time loss during the process and the loss of pneumoperitoneum, (b) smokelessness allows to work in clear operative field and also avoids the need for smoke evacuation and loss of pneumoperitoneum, and (c) lower incidence of GB perforation in the CLC group (7 vs 12), thereby avoiding the time loss in retrieving the spilled stone and lavage.

The lateral energy spread is less with ultrasonic shears (1.5 $\mathrm{mm}$ vs $0.5 \mathrm{~cm}$ in electrocautery) ${ }^{2}$ therefore, there is a decreased chance of GB perforation, spillage of gallstone and bile, and biliary peritonitis. After spillage, there is obvious increase in the duration of surgery due to the time take for suction-irrigation, retrieval of spilled stones, and poor field and visibility. ${ }^{12,20}$ We had slightly higher rate of $\mathrm{GB}$ perforation in the $\mathrm{CL}$ group, though statistically not significant; and the mean operative time in patients with $G B$ perforation was shorter in the CLC though it was not statistically ( $p$ 0.34) significant. In patients without GB perforation, the operative time was significantly less in the CLC group. When the GB perforation complicated the procedure, it does significantly increases the operative time in both the groups and the time taken is comparable. ${ }^{12,20}$ Different studies have reported the incidence of GB perforation during the LC ranging from $10 \%$ to $50 \% .{ }^{9,20}$ In our study, $17 \%$ patients had perforated GB. Janssen et al. ${ }^{9}$ also had a similar lower incidence of GB perforation with ultracision removal of GB (16 vs $50 \%$, respectively; $p$ 0.001) and also found that the risk of GB perforation with bile (four times higher) and stone (six times higher) spillage was significantly higher in the electrocautery group. 
Jain et al. ${ }^{12}$ in his prospective randomized control study reported significantly less time to remove GB from its bed using ultrasonic shears (nearly 4 minutes vs 7.36 minutes with electrocautery, $p$ 0.001). We had similar experience, though it was not statistically significant in our study. The difference is because ultrasonic shear is all in one tool for the procedure (dissection, ligation of the duct and artery, and removal of GB from the liver bed). Besides, ultrasonic device has been said to produce small vacuoles or cavitation which enlarge and separate the tissue, ${ }^{13}$ making it easy to separate the $G B$ from the GB bed. Even in the case of inflammation where the tissue is tougher, vascular, and more fibrous, the ultrasonic energy and its hemostatic ability keep the operative field clear, decreasing the operative time and avoiding inadvertent injuries.

The CLC group demonstrated less need for drainage. The decreased drain placement led to reduced pain scores, early discharge, and decreased morbidity. The drain was placed according to the operative surgeon's preference. It was kept for those who had bleeding/oozing, bile stain, or in difficult dissections. In our study, the drain was removed mostly within 48 hours (median 2 days) though few of our patients required a prolonged drainage. Less need for abdominal drain in the CLC group is also one of the contributing factors for less operative time and morbidity.

The reported conversion to open cholecystectomy rate in the literature is $1.2-8.2 \% .{ }^{13,22-24}$ We had three (2.6\%) conversions, one (1.85\%) in the CLC group and two (3.2\%) in the CL group. Conversion rate in the prospective study by Hüscher et al. ${ }^{2}$ was even lower $(0.87 \%)$ than that in the literature and showed theoretical benefits of ultrasonic dissection. The reasons for conversion in different studies $2,22,25,26$ varied between the two subgroups, i.e., surgeon in training and expert. But, in general, conversion was due to the dense adhesion/frozen Calot's triangle, intraoperative complications, difficult anatomy, or inability to identify the structures. Difficult anatomy of the Calot's triangle was the only reason for $4 \%$ conversion rate in the study by Jain et al., ${ }^{12}$ and it was equal in both the groups. Our reason for conversion in the $C L$ group was obscured anatomy and bleeding, and another case had dilated CBD with multiple calculi requiring an open choledochoduodenostomy.

Alexander ${ }^{23}$ has extensively described the causes of pain after laparoscopy. The major cause of post laparoscopic pain was attributed to the sudden distension/stretching of the peritoneum, leading to the traumatic traction of the nerves, vessel injury, and release of the inflammatory mediators. In addition, phrenic nerve irritation due to gas used for the pneumoperitoneum was pointed out to be responsible for the prolonged persistence of shoulder tip pain. ${ }^{27}$ The use of ultrasonic shear led to (a) minimal lateral thermal injury, minimal damage to the surrounding nerves, and minimal tissue charring, and, therefore, minimal inflammation and less release of inflammatory mediators, ${ }^{12}$ (b) decreased operative time contributing to less pneumoperitoneum-related peritoneal distension. This may have accounted for low pain score in the CLC group. The significant difference in pain scores was obtained between the two groups in the first 12 hours and it was more with the $\mathrm{CL}$ group $(p<0.01)$. No significant differences were obtained in the pain scores in the first week after surgery. The postoperative analgesic requirement was less in the ultrasonic shear group compared with the electrocautery group ( 1.89 vs $2.66 ; p 0.001)$ in the study by Jain et al., ${ }^{12}$ but in our study analgesic requirement in both the groups was similar, which may be because patients were given analgesia even when they had low pain score on their demand.
The postoperative fall in hemoglobin was significantly less in the CLC group $(0.40 \mathrm{~g} / \mathrm{dL}$ vs $0.70 \mathrm{~g} / \mathrm{dL} ; p 0.001)$, though there was no incidence of clinically significant (severe) bleeding in either group requiring blood transfusion, the sole reason for conversion. The conversion requirement was more because of the difficult anatomy, not solely because of bleeding. This significant difference may be because of minor to moderate bleeding in the $\mathrm{CL}$ group. On the contrary, ultrasonic shear is known for hemostasis. It coagulates before separating the tissue and stays between the planes, so there is decreased bleeding and oozing from the surfaces.

No surgery is without complication. Laparoscopic cholecystectomy is the most common elective surgery being performed worldwide, and research has proved its perfection to avoid associated complications. Clipless laparoscopic cholecystectomy is one of the techniques that needs to be addressed. As with any new procedure, fear and hesitancy to adopt this noble technique can be observed. Hüscher et al. ${ }^{28}$ has histologically confirmed the effective sealing of the cystic duct stump by the harmonic shears. Post LC bile leak can give the surgeon sleepless nights. This can be the main reason why most of the surgeons hesitate to perform CLC. This myth has been challenged in the recent days, providing better outcome and sound sleep for surgeons. By using ultrasonic shear closure, division of vessels up to $5 \mathrm{~mm}$ can be done safely. ${ }^{2,14,29-37}$ We had a total of $6.25 \%$ morbidity following the surgery; however, no mortality was reported in either group. Two (3.77\%) patients had morbidity in the CLC group and five (8.47\%) in the CL group ( $p$ 0.44). Three $(2.67 \%)$ patients in our study had bilious drainage, one $(1.88 \%)$ in the CLC group and two (3.38\%) in the CL group. All were managed with drains and none required further interventions. In the present study, one case in the CLC group (1.88\%) had port site infection and two cases (3.38\%) in the CL group had port site infection and a single case (1.69) had chest infection. Bessa et al.'s ${ }^{20}$ finding also did not report any bile leak in either group, demonstrating the effectiveness of harmonic shears in closing the duct as safely as with the application of metallic clips. This capability, safety, and efficacy of harmonic shears in sealing and dividing the cystic duct without increasing the complication rate also have been demonstrated in other studies. ${ }^{2,10,20}$ In the present study, as well as in the Westervelt and Bessa et al. ${ }^{10,20}$ studies, the harmonic shears were applied to only one side of the cystic duct where sealing and division were achieved, with no bile leaks from the cystic duct stump encountered in any of the two studies. So the double application of the harmonic shears to the cystic duct as explain by Hüscher et al. ${ }^{2}$ may be unnecessary and an unsafe practice. ${ }^{2,10,20}$ Lateral energy spread is the other mechanism for bile duct injury. Unlike the $\mathrm{CL}$ group which witnessed high chances of lateral thermal injury to the bile duct, ultrasonic instruments cause negligible lateral damage. ${ }^{36,37}$ In the present study, the low incidence of the bile duct leak or injury in the CLC group (1.88\%) is not only comparable to the $\mathrm{CL}$ group but also within the acceptable range of bile duct injury following LC. Also, the leak that we had in the CLC group was a minor duct injury, which was managed successfully with pigtail catheter.

Most of the patients in our study were discharged on the first postoperative day following surgery and was not significant between the groups ( $p$ 0.23), though there was significantly less hospital stay in the ultrasonic group in other studies. ${ }^{2,12}$ Shorter duration has been attributable to the less number of patients requiring drainage and less incidence of GB perforation, leading to localized peritonitis and less pain. 


\section{Conclusion}

Laparoscopic cholecystectomy is now the gold standard procedure for gallstone disease. With the development of ultrasonic energy source and its ability to seal the vessel and cystic duct safely up to $5 \mathrm{~mm}$ diameter, it can be safely utilized during $\mathrm{LC}$ without the need of clips. It safeguards the complication related to the clips used in the $\mathrm{CL}$ technique and decreases the operative time, GB perforation, and immediate postoperative pain and avoids drain requirement and blood loss without increasing the morbidity or mortality.

\section{References}

1. Soper NJ, Stockmann PT, Dunnegan DL, et al. Laparoscopic cholecystectomy. The new "gold standard"? Arch Surg 1992;127(8): 917-921.; discussion 921-923 10.1001/archsurg.1992.01420080051008.

2. HüscherCGS, Lirici MM, Di Paola M, et al.Laparoscopiccholecystectomy by ultrasonic dissection without cystic duct and artery ligature. Surg Endosc 2003;17(3):442-451. DOI: 10.1007/s00464-002-9068-3.

3. Cetta F, Lombardo F, Cariati A. The role of the content (decreased level of apolipoprotein A1) and of the container (bile duct stricture, sectorial dilatation of the ducts determining bile stasis) in the pathogenesis of hepatolithiasis, either pigment or cholesterol. Hepatology 1994;19(6):1539-1541. DOI: 10.1002/hep.1840190637.

4. Hanazaki K, Igarashi J, Sodeyama H, et al. Bile leakage resulting from clip displacement of the cystic duct stump: a potential pitfall of laparoscopic cholecystectomy. Surg Endosc 1999;13(2):168-171. DOI: $10.1007 / \mathrm{s} 004649900932$.

5. Nelson MT, Nakashima M, Mulvihill SJ. How secure are laparoscopically placed clips? An in vitro and in vivo study. Arch Surg 1992;127(6): 718-720. DOI: 10.1001/archsurg.1992.01420060094014.

6. Gigot J, Etienne J, Aerts R, et al. The dramatic reality of biliary tract injury during laparoscopic cholecystectomy. An anonymous multicenter Belgian survey of 65 patients. Surg Endosc 1997;11(12):1171-1178. DOI: $10.1007 / \mathrm{s} 004649900563$.

7. Lillemoe KD, Petrofski JA, Choti MA, et al. Isolated right segmental hepatic duct injury: a diagnostic and therapeutic challenge. J Gastrointest Surg 2000;4(2):168-177. DOI: 10.1016/S1091255X(00)80053-0.

8. Usal H, Sayad P, Hayek N, et al. Major vascular injuries during laparoscopic cholecystectomy. An institutional review of experience with 2589 procedures and literature review. Surg Endosc 1998;12(7):960-962. DOI: 10.1007/s004649900756.

9. Janssen IMC, Swank DJ, Boonstra O, et al. Randomized clinical trial of ultrasonic vs electrocautery dissection of the gallbladder in laparoscopic cholecystectomy. Br J Surg 2003;90(7):799-803. DOI: $10.1002 / b j s .4128$.

10. Westervelt J. Clipless cholecystectomy: broadening the role of the harmonic scalpel. JSLS 2004;8(3):283-285.

11. Minutolo V, Gagliano G, Rinzivillo C, et al. Usefullness of the ultrasonically activated scalpel in laparoscopic cholecystectomy: our experience and review of literature. G Chir 2008;29(5):242-245.

12. Jain SK, Tanwar R, Kaza RCM, et al. A prospective, randomized study of comparison of clipless cholecystectomy with conventional laparoscopic cholecystectomy. J Laparoendosc Adv Surg Tech A 2011;21(3):203-208. DOI: 10.1089/lap.2010.0455.

13. Shikata S, Noguchi Y, Fukui T. Early vs delayed cholecystectomy for acute cholecystitis: a meta-analysis of randomized controlled trials. Surg Today 2005;35(7):553-560. DOI: 10.1007/s00595-005-2998-3.

14. Lau H, Lo CY, Patil NG, et al. Early vs delayed-interval laparoscopic cholecystectomy for acute cholecystitis: a metaanalysis. Surg Endosc 2006;20(1):82-87. DOI: 10.1007/s00464-005-0100-2.

15. Gurusamy KS, Samraj K. Early vs delayed laparoscopic cholecystectomy for acute cholecystitis. Cochrane Database Syst Rev 2006;4:CD005440. DOI: 10.1002/14651858.CD005440.pub2.

16. Siddiqui T, MacDonald A, Chong PS, et al. Early vs delayed laparoscopic cholecystectomy for acute cholecystitis: a meta-analysis of randomized clinical trials. Am J Surg 2008;195(1):40-47. DOI: 10.1016/j.amjsurg.2007.03.004.

17. Catena F, Ansaloni L, Di Saverio S, et al. Prospective analysis of 101 consecutive cases of laparoscopic cholecystectomy for acute cholecystitis operated with harmonic scalpel. Surg Laparosc Endosc Percutan Tech 2009;19(4):312-316. DOI: 10.1097/ SLE.0b013e3181b16662.

18. Fullum TM, Kim S, Dan D, et al. Laparoscopic "Dome-down" cholecystectomy with the LCS-5 harmonic scalpel. JSLS 2005;9(1): 51-57.

19. Power C, Maguire D, McAnena OJ, et al. Use of the ultrasonic dissecting scalpel in laparoscopic cholecystectomy. Surg Endosc 2000;14(11):1070-1073. DOI: 10.1007/s004640000034.

20. Bessa SS, Al-Fayoumi TA, Katri KM, et al. Clipless laparoscopic cholecystectomy by ultrasonic dissection. J Laparoendosc Adv Surg Tech A 2008;18(4):593-598. DOI: 10.1089/lap.2007.0227.

21. Kandil T, El Nakeeb A, El Hefnawy E. Comparative study between clipless laparoscopic cholecystectomy by harmonic scalpel vs conventional method: a prospective randomized study. J Gastrointest Surg 2010;14:323-328. DOI: 10.1007/s11605-009-1039-8.

22. Targarona EM, Marco $C$, Balagué $C$, et al. How, when, and why bile duct injury occurs. A comparison between open and laparoscopic cholecystectomy. Surg Endosc 1998;12(4):322-326. DOI: 10.1007/ s004649900662.

23. Alexander J. Pain after laparoscopy. Br J Anaesth 1997;79(3):369-378. DOI: $10.1093 / \mathrm{bja} / 79.3 .369$.

24. Alexander JI. Draining intraperitoneal gas after laparoscopy. Anaesthesia 2002;57(6):57618-57619. DOI: 10.1046/j.13652044.2002.265817.x.

25. Regoly-Merei J, Ihasz M, Szeberin Z, et al. Biliary tract complications in laparoscopic cholecystectomy. Surg Endosc 1998;12(4):294-300. DOI: $10.1007 / \mathrm{s} 004649900657$.

26. Thompson MH, Benger JR. Cholecystectomy, conversion and complications. HPB Surg 2000;11(6):373-378. DOI: 10.1155/2000/56760.

27. Wills E, Crawford G. Clipless vs conventional laparoscopic cholecystectomy. J Laparoendosc Adv Surg Tech A 2013;23(3): 237-239. DOI: 10.1089/lap.2012.0387.

28. Hüscher CG, Lirici MM, Anastasi A, et al. Laparoscopic cholecystectomy by harmonic dissection. Surg Endosc 1999;13(12):1256-1257.

29. Redwan AA. Single-working-instrument, double-trocar, clipless cholecystectomy using harmonic scalpel: a feasible, safe, and less invasive technique. J Laparoendosc Adv Surg Tech A 2010;20(7): 597-603. DOI: 10.1089/lap.2009.0375.

30. Kavlakoglu B, Pekcici R, Oral S. Verification of clipless closure of cystic duct by harmonic scalpel. J Laparoendosc Adv Surg Tech A 2010;20(7):591-595. DOI: 10.1089/lap.2010.0222.

31. Ramos AC, Ramos MG, Galvão-Neto MdP, et al. Total clipless cholecystectomy by means of harmonic sealing. Arq Bras Cir Dig 2015;28(1):53-56. DOI: 10.1590/s0102-67202015000100014.

32. Swanstrom LL. "Clipless" cholecystectomy: evolution marches on, even for lap chole. World J Surg 2011;35(4):824-825. DOI: 10.1007/ s00268-011-0974-1.

33. Entezari K, Hoffmann P, Goris M, et al. A review of currently available vessel sealing systems. Minim Invasive Ther Allied Technol 2007;16(1):52-57. DOI: 10.1080/13645700601181414.

34. Kavlakoglu B, Pekcici R, Oral S. Clipless cholecystectomy: which sealer should be used? World J Surg 2011;35(4):817-823. DOI: 10.1007/ s00268-010-0819-3.

35. Suo G, Xu A. Clipless minilaparoscopic cholecystectomy: a study of 1,096 cases. J Laparoendosc Adv Surg Tech A 2013;23(10):849-854. DOI: 10.1089/lap.2012.0561.

36. Richardson MC, Bell G, Fullarton GM. Incidence and nature of bile duct injuries following laparoscopic cholecystectomy: an audit of 5913 cases. Br J Surg 1996;83(10):1356-1360. DOI: 10.1002/bjs.1800831009.

37. Shea JA, Healey MJ, Berlin JA, et al. Mortality and complications associated with laparoscopic cholecystectomy. A meta-analysis. Ann Surg 1996;224(5):609-620. DOI: 10.1097/00000658-199611000-00005. 